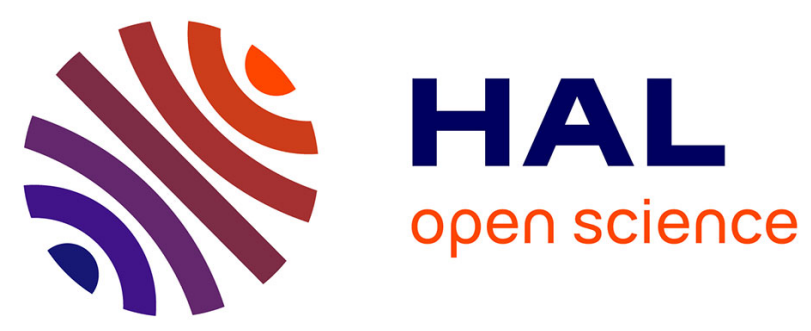

\title{
Low Temperature Kinetics of the Reaction Between Methanol and the CN Radical
}

Divita Gupta, Sidaty Cheikh Sid Ely, Ilsa R. Cooke, Théo Guillaume, Omar Abdelkader Khedaoui, Thomas Hearne, Brian Hays, Ian R Sims

\section{- To cite this version:}

Divita Gupta, Sidaty Cheikh Sid Ely, Ilsa R. Cooke, Théo Guillaume, Omar Abdelkader Khedaoui, et al.. Low Temperature Kinetics of the Reaction Between Methanol and the CN Radical. Journal of Physical Chemistry A, 2019, 123 (46), pp.9995-10003. 10.1021/acs.jpca.9b08472 . hal-02360549

\section{HAL Id: hal-02360549 \\ https://hal.science/hal-02360549}

Submitted on 3 Feb 2020

HAL is a multi-disciplinary open access archive for the deposit and dissemination of scientific research documents, whether they are published or not. The documents may come from teaching and research institutions in France or abroad, or from public or private research centers.
L'archive ouverte pluridisciplinaire HAL, est destinée au dépôt et à la diffusion de documents scientifiques de niveau recherche, publiés ou non, émanant des établissements d'enseignement et de recherche français ou étrangers, des laboratoires publics ou privés. 


\section{Low Temperature Kinetics of the Reaction Between Methanol and the CN Radical}

Divita Gupta, Sidaty Cheikh Sid Ely, Ilsa R. Cooke, Théo Guillaume, Omar Abdelkader

Khedaoui, Thomas S. Hearne, Brian M Hays, Ian R. Sims*

Univ Rennes, CNRS, IPR (Institut de Physique de Rennes) - UMR 6251, F-35000

Rennes, France

*Corresponding author: email ian.sims@univ-rennes1.fr

\section{Roles of authors}

\begin{tabular}{|l|l|}
\hline Author & Role \\
\hline Divita Gupta & $\begin{array}{l}\text { Experimental measurements using EM II (see text). } \\
\text { Theoretical calculations. Drafting and correction of article. }\end{array}$ \\
\hline Sidaty Cheikh Sid Ely & Experimental measurements using EM I (see text). \\
\hline Ilsa R. Cooke & $\begin{array}{l}\text { Experimental measurements using EM II (see text). } \\
\text { Drafting and correction of article. }\end{array}$ \\
\hline Théo Guillaume & Laser setup for EM II \\
\hline $\begin{array}{l}\text { Omar Abdelkader } \\
\text { Khedaoui }\end{array}$ & $\begin{array}{l}\text { Design, 3D printing fabrication and testing of lowest T } \\
\text { Laval nozzle used for EM II }\end{array}$ \\
\hline Thomas S. Hearne & $\begin{array}{l}\text { Construction and operation of Controlled Evaporator Mixer } \\
\text { system for EM II }\end{array}$ \\
\hline Brian M Hays & Laser alignment for EM II \\
\hline Ian R. Sims & $\begin{array}{l}\text { Scientific direction of project, participation in EM I } \\
\text { measurements, correction of article. }\end{array}$ \\
\hline
\end{tabular}




\begin{abstract}
Methanol $\left(\mathrm{CH}_{3} \mathrm{OH}\right)$ is considered by astronomers to be the simplest complex organic molecule $(\mathrm{COM})$ and has been detected in various astrophysical environments, including protoplanetary disks, comets, and the interstellar medium (ISM). Studying the reactivity of methanol at low temperatures will aid our understanding of the formation of other complex, and potentially prebiotic molecules. A major destruction route for many neutral COMs, including methanol, is via their reactions with radicals such as $\mathrm{CN}$, which is ubiquitous in space. Here, we study the kinetics of the reaction between methanol and the $\mathrm{CN}$ radical using the well-established CRESU technique (a French acronym standing for Reaction Kinetics in Uniform Supersonic Flow) combined with Pulsed Laser Photolysis - LaserInduced Fluorescence (PLP-LIF). Electronic structure calculations were also performed to identify the exothermic channels through which this reaction can proceed. Our results for the rate coefficient, are represented by the modified Arrhenius equation, $k(T)=1.26 \times 10^{-11}$ $(T / 300 \mathrm{~K})^{-0.7} \exp (-5.4 \mathrm{~K} / T)$ and display a negative temperature dependence over the temperature range $16.7-296 \mathrm{~K}$, which is typical of what has been seen previously for other radical-neutral reactions that do not possess potential energy barriers. The rate coefficients obtained at room temperature strongly disagree with a previous kinetics study, which is currently available in the Kinetics Database for Astrochemistry (KIDA) and therefore used in some astrochemical models.
\end{abstract}




\section{Introduction}

The interstellar medium is host to a rich chemistry that produces a variety of species, including those with six or more atoms that have been named complex organic molecules (COMs). ${ }^{1}$ While the abundance of many COMs in the gas-phase has been explained by their formation and desorption from icy dust grain surfaces, ${ }^{2-4}$ COMs have also been detected in very cold $(<10 \mathrm{~K})$ environments where thermal desorption from ices is prohibited, suggesting a possible role of gas-phase formation routes at these low temperatures..$^{5-7}$

For a long time, reactions between two neutral species had not been considered to play a major role at the low temperatures and densities of the interstellar medium (ISM). Over the past couple of decades, however, the importance of neutral-neutral reactions has become well established as many of these reactions are barrierless, involve an initial weakly bound complex or proceed through submerged barriers - meaning that many of these reactions continue at a sufficiently fast rate even at low temperatures. ${ }^{8-12}$ Given the difficulty in performing gas-phase kinetics experiments and theoretical calculations at low temperatures, kinetics data for most of the reactions expected to take place in interstellar and planetary environments are missing. In the absence of low temperature data, many models either extrapolate from the room temperature rate coefficients or take the value as measured at room temperature over the whole temperature range, often down to $10 \mathrm{~K}^{7,13}$

Methanol was first detected in Sagittarius A and B2 ${ }^{14}$ and has since been detected in various sources including galactic H II regions,,${ }^{15}$ pre-stellar cores, ${ }^{16,17}$ ISM clouds, ${ }^{18}$ protostellar sources, ${ }^{19,20}$ protoplanetary disks, ${ }^{21}$ and comets. ${ }^{22,23}$ The abundance of methanol is one of the highest amongst the COMs, as high as $3 \times 10^{-5}$ with respect to $\mathrm{H}_{2}$ in some sources. ${ }^{1}$ Explaining the abundance of methanol in these sources requires accurate kinetic measurements (either experimental or theoretical) of the various routes involved in both its formation and destruction. 
Rate coefficients for bimolecular reactions are often measured under pseudo-first order conditions, in which the concentration of one of the neutral species (usually a stable molecule) must be accurately known. Given the low saturated vapor pressure of most COMs below $200 \mathrm{~K}$, kinetics studies of their reactivity at low temperature can be difficult. Gas cooling by collisions with cold walls in cryogenically cooled cells can only be used down to about $200 \mathrm{~K}$, except for certain light species like CO where lower temperatures can be achieved, before condensation on the cell walls causes large uncertainties in the gas concentration. $^{24,25}$ Free jet expansions have been used extensively in spectroscopy to produce cold gas; however, the density and temperature vary strongly along the beam making them unsuitable for kinetics measurements. The CRESU technique, an essentially wall-less cooling method, allows precise control over these parameters. It involves an expansion of gas from a high-pressure region to a low-pressure region through a particular type of convergent-divergent nozzle called a Laval nozzle. This expansion results in a beam of cold gas that is uniform in velocity, temperature, and density typically for several tens of centimeters. Rowe and co-workers ${ }^{26}$ developed the use of CRESU flows to study gasphase kinetics and this technique has since been used to characterize many ion-neutral reactions, ${ }^{27-31}$ neutral-neutral reactions, ${ }^{8,12,32-36}$ and collisional energy transfer processes. ${ }^{37-}$ ${ }^{40} \mathrm{~A}$ detailed summary of the reactions studied using the CRESU technique was published recently. ${ }^{41}$

Radical-neutral reactions are thought to be an important destruction route for gas-phase methanol at low temperatures. The rate coefficients for the reactions of methanol with other radicals such as $\mathrm{OH}^{36}$ and $\mathrm{C}\left({ }^{3} \mathrm{P}\right)^{42}$ have been measured experimentally using the CRESU technique and were found to remain rapid at low temperatures relevant to the cold ISM. The $\mathrm{CN}$ radical has been found in many astronomical sources, ${ }^{43-46}$ and $\mathrm{CN}$ chemistry has been shown to play an important role in Titan's atmosphere. ${ }^{47-49}$ Thus, the reaction with $\mathrm{CN}$ radicals is a feasible destruction route for methanol in a range of low temperature

\footnotetext{
${ }^{a}$ Cinétique de Réaction en Ecoulement Supersonique Uniforme: A French acronym standing for Reaction Kinetics in Uniform Supersonic Flow
} 
environments. One of the expected products of this reaction, the methoxy radical $\left(\mathrm{CH}_{3} \mathrm{O}\right)$, has been detected in the cold source Barnard $1 b^{50}$ and there has been a significant discussion concerning its abundance compared to its isomer, hydroxymethyl radical $\left(\mathrm{CH}_{2} \mathrm{OH}\right)$, which has not been detected yet. In the low-temperature conditions of Barnard $1 \mathrm{~b}$, non-thermal mechanisms must be invoked if methoxy formation is expected to occur on dust grains, as $\mathrm{CH}_{3} \mathrm{O}$ and $\mathrm{CH}_{2} \mathrm{OH}$ cannot thermally desorb from ice surfaces. However, ice-phase experiments on the photodissociation of methanol suggest the $\mathrm{CH}_{2} \mathrm{OH}$ isomer is favored and therefore it has been suggested that the methoxy radical abundance could be explained by its formation in the gas-phase. ${ }^{51}$ In particular, the reaction between methanol and the $\mathrm{OH}$ radical has been discussed as a source of $\mathrm{CH}_{3} \mathrm{O} / \mathrm{CH}_{2} \mathrm{OH}$, but the branching ratio into the two channels has not yet been fully characterized. ${ }^{12,36,51}$

To the best of our knowledge, no previous experiments have been published for the reaction of $\mathrm{CN}$ radicals with methanol below room temperature. The earliest study at room temperature was conducted by Sayah and co-workers ${ }^{52}$ who performed flow-tube experiments using photo-dissociation of $\mathrm{C}_{2} \mathrm{~N}_{2}$ at $193 \mathrm{~nm}$ as their source of $\mathrm{CN}$ radicals. They determined a rate coefficient of $(1.2 \pm 0.2) \times 10^{-10} \mathrm{~cm}^{3} \mathrm{~s}^{-1}$ which is different by an order of magnitude from a later study by Janssen and Hershberger, ${ }^{53}$ who report a value of $(1.03 \pm 0.10) \times 10^{-11} \mathrm{~cm}^{3} \mathrm{~s}^{-1}$ at room temperature. Janssen and Hershberger used photolysis of ICN at $266 \mathrm{~nm}$ to produce the $\mathrm{CN}$ radicals and studied the reaction using time-resolved infrared diode laser absorption spectroscopy, allowing them also to investigate the reaction products.

Here, the rate coefficients for the reaction of methanol with the $\mathrm{CN}$ radical over a wide temperature range of $16.7-296 \mathrm{~K}$ using the CRESU technique are presented. First the experimental and theoretical methodologies used in these measurements are detailed followed by the rate coefficients and their dependence on temperature, and a discussion of the implications of the results and their astrophysical importance is given. These measurements can be input into astrochemical models in order to assess the importance of the reaction as a destruction route for methanol at various temperatures. 


\section{Experimental Methodology}

The kinetics of the reaction between the $\mathrm{CN}$ radical and methanol were measured using the Pulsed-Laser Photolysis-Laser Induced Fluorescence (PLP-LIF) technique. The low temperatures, down to $16.7 \mathrm{~K}$, were achieved using the CRESU technique (a French acronym standing for Reaction Kinetics in Uniform Supersonic Flow), which has been described in detail in previous publications, ${ }^{37,41,54}$ and will only be described in brief here. Figure 1 shows a schematic of the CRESU technique configured for the study of neutralneutral reaction kinetics using PLP-LIF. ${ }^{41}$ A dilute mixture (typically $<1 \%$ ) of the reactant and radical precursor in a buffer gas $\left(\mathrm{He}, \mathrm{Ar}\right.$, or $\left.\mathrm{N}_{2}\right)$ expands isentropically from a highpressure region (reservoir), into a low-pressure region (chamber) through a convergentdivergent Laval nozzle to generate a cold supersonic flow that is uniform in temperature and density. Given the high density of the molecules $\left(10^{16}-10^{17} \mathrm{~cm}^{-3}\right)$ in the flow, collisions between the molecules ensure thermal equilibrium is maintained, typically for tens of centimeters. A wide range of temperatures can be reached by careful manipulation of the physical dimensions of the nozzle (in particular the throat diameter), the buffer gas used, and the flow conditions/pumping capacity, which varies the pressure in the reservoir and in the chamber. Characterizing the flow temperature is essential to study chemical kinetics and was performed using impact pressure measurements ${ }^{54}$ for each nozzle prior to undertaking kinetics experiments.

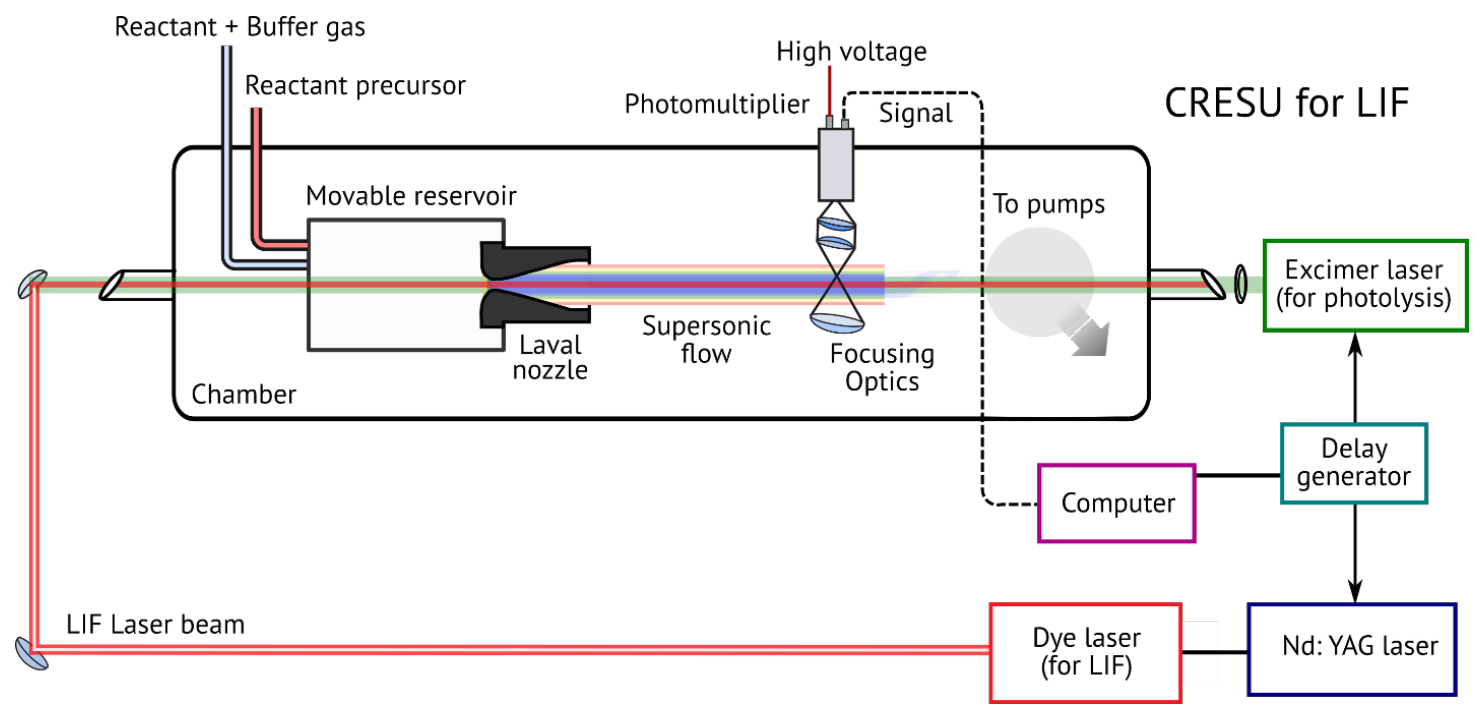


Figure 1. Schematic of the CRESU setup at Université de Rennes 1, used for the study of the kinetics of the reaction of methanol with the $\mathrm{CN}$ radical. The reactant gas mixture expands through a Laval nozzle from the high-pressure reservoir into the low-pressure chamber creating a uniform supersonic flow. An excimer laser is used for the generation of the $\mathrm{CN}$ radicals and a dye laser pumped by the third harmonic of a pulsed Nd:YAG laser is used for LIF and is aligned along the path of the flow and the excimer laser. A photomultiplier tube along with the corresponding optics is used to record the fluorescence signal. The laser timings and delays are controlled using a delay generator. Reprinted from Cooke \& Sims, $2019 .{ }^{41}$

Two methods were used to perform the experiments, as the first set of measurements at room temperature deviated significantly from previous measurements made by Sayah and co-workers. ${ }^{52}$ In the first method, hereon referred to as EM I, gas mixtures were made in a Teflon coated stainless steel container by careful control of the partial pressures of methanol vapor and the buffer gas. Different concentrations of methanol could be obtained by varying the pressure of the buffer gas. A solid sample of ICN was placed on a frit (porous glass) in a glass vessel and introduced into the chamber via a controlled flow of buffer gas ( $200 \mathrm{sccm})$. The fourth harmonic output of a Nd:YAG laser (Spectra Physics GCR 190) at $266 \mathrm{~nm}$ was used to photo-dissociate ICN (Acros Organics, 98\%) at a laser fluence in the reaction zone of $\sim 35 \mathrm{~mJ} \mathrm{~cm}^{-2}$, producing $\mathrm{CN}$ radicals largely in the $v=0$ level of the $X^{2} \Sigma^{+}$state. In the second method, referred to as EM II hereinafter, a Controlled Evaporation and Mixing system (CEM) was used to introduce methanol into the flow. A stainless steel vessel containing methanol was pressurized with nitrogen and a flow of liquid methanol was passed via a Coriolis liquid flow meter (Bronkhorst mini CORIFLOW ML120V00) into an evaporator (Bronkhorst W-202A-222-K), and was mixed with a controlled flow of buffer gas via a thermal mass flow controller (Bronkhorst EL-FLOW Prestige). The $\mathrm{CN}$ radicals were generated by photodissociation of ICN (Acros Organics, 98\%) at $248 \mathrm{~nm}$ using a $\mathrm{KrF}$ excimer laser (Coherent LPXPro 210) at a laser fluence in the reaction zone of $\sim 25 \mathrm{~mJ} \mathrm{~cm}^{-2}$. Photodissociation of ICN at this wavelength also produces 
$\mathrm{CN}$ radicals primarily ( $\gtrsim 93 \%)$ in the $v=0$ level of the $X^{2} \Sigma^{+}$state..$^{55}$ At both wavelengths, rapid rotational relaxation is assured by collisions with the cold, dense buffer gas.

In both the methods, the LIF/fluorescence signal was then recorded by excitation in the $(0,0)$ band of the $B^{2} \Sigma^{+}-X^{2} \Sigma^{+}$electronic transition at $388.3 \mathrm{~nm}$ using a dye laser (Laser Analytical Systems, LDL 20505, operating with 0.2g/L mixture of Exciton Exalite 389 dye in 1,4-dioxane) pumped by the frequency-tripled output at $355 \mathrm{~nm}$ of a Nd:YAG laser (Continuum, Powerlite Precision II). A narrowband interference filter centered at $420 \mathrm{~nm}$ (Ealing Optics) was used with a photomultiplier tube (PMT, Thorn EMI 6723) to select the off-resonant fluorescence into the first vibrational level of the ground state via the $(0,1)$ band. As the start of the reaction is marked by the initiation of ICN photolysis, delays in the range of zero to hundreds of $\mu$ s between the excimer and the LIF laser pulses, both operating at $10 \mathrm{~Hz}$, allowed us to record the time dependence of the $\mathrm{CN}$ radical depletion during the reaction.

The experiments were performed under pseudo-first order conditions with methanol in excess. The absorption cross-section of ICN has been reported as $3 \times 10^{-19} \mathrm{~cm}^{2}$ at $266 \mathrm{~nm}^{56}$ and $4.7 \times 10^{-19} \mathrm{~cm}^{2}$ at $248 \mathrm{~nm} \cdot{ }^{57}$ Given the density of ICN in the gas flow $\left(\sim 10^{12} \mathrm{~cm}^{-3}\right)$, an estimated maximum $\mathrm{CN}\left(X^{2} \Sigma^{+}\right)$concentration of $\sim 1 \times 10^{10} \mathrm{~cm}^{-3}$ in either condition (EM I or EM II) was obtained at the laser fluences used, which is lower than the concentration of methanol used by a factor of at least 100 .

The LIF signals were recorded by a gated integrator (Stanford Research Systems) at 200 evenly-spaced time delays and were averaged typically 5-10 times. These were fit to single exponential decays, yielding pseudo-first order rate coefficients. Linear plots of these pseudo-first order rate coefficients versus the methanol concentration were then used to calculate the second-order rate coefficient. The procedure was repeated for multiple temperatures using different Laval nozzles. The experimental parameters and rate coefficients measured for each temperature are summarized in Table 1. 
Table 1. a: Experiments performed using EM I

b: Experiments performed using EM II

Rate coefficients for the reaction of the $\mathrm{CN}$ radical with methanol measured at different temperatures, with the associated experimental parameters. Quoted uncertainties are calculated using the standard error evaluated from the second order plot, multiplied by the appropriate Student's $t$ factor for $95 \%$ confidence, and then combined with an estimated systematic error of $10 \%$. Entries in bold are variance weighted mean values of rate coefficients at the same temperature, calculated using statistical uncertainties only, where the resulting uncertainty is then combined in quadrature with an estimated systematic error of $10 \%$.

\begin{tabular}{|c|c|c|c|c|c|}
\hline$T(\mathbf{K})$ & Buffer gas & $\begin{array}{c}\text { Total density } \\
\left(10^{16} \mathrm{~cm}^{-3}\right)\end{array}$ & $\begin{array}{c}\text { Range of } \\
{\left[\mathrm{CH}_{3} \mathrm{OH}\right]} \\
\left(10^{13} \mathrm{~cm}^{-3}\right)\end{array}$ & $\begin{array}{c}\text { No. of } \\
\text { experimental } \\
\text { points }\end{array}$ & $\begin{array}{l}\text { Rate coefficient } \\
k\left(10^{-11} \mathrm{~cm}^{3} \mathrm{~s}^{-1}\right)\end{array}$ \\
\hline 16.7 & $\mathrm{He}^{\mathbf{b}}$ & 4.89 & $0.90-6.50$ & 9 & $7.4 \pm 1.2$ \\
\hline \multirow[t]{3}{*}{24} & $\mathrm{He}^{\mathrm{a}}$ & 18.30 & $0.00-8.94$ & 8 & $5.82 \pm 0.63$ \\
\hline & $\mathrm{He}^{\mathbf{a}}$ & 18.30 & $0.00-5.81$ & 10 & $6.82 \pm 0.77$ \\
\hline & & & & & $6.1 \pm 0.6$ \\
\hline 36 & $\mathrm{He}^{\mathrm{a}}$ & 5.28 & $0.00-3.64$ & 7 & $5.4 \pm 0.6$ \\
\hline 52.8 & $\mathrm{Ar}^{\mathrm{a}}$ & 20.20 & $0.00-6.72$ & 7 & $3.7 \pm 0.5$ \\
\hline 71.5 & $\mathrm{~N}_{2}{ }^{\mathbf{a}}$ & 5.79 & $0.00-6.22$ & 9 & $3.2 \pm 0.4$ \\
\hline \multirow[t]{3}{*}{82.6} & $\mathrm{~N}_{2}{ }^{\mathrm{b}}$ & 4.88 & $0.97-9.74$ & 12 & $3.37 \pm 0.84$ \\
\hline & $\mathrm{N}_{2}{ }^{\mathbf{b}}$ & 4.88 & $0.96-9.01$ & 6 & $2.96 \pm 1.30$ \\
\hline & & & & & $3.3 \pm 0.7$ \\
\hline 97.4 & $\mathrm{Ar}^{\mathrm{a}}$ & 15.45 & $0.00-12.14$ & 8 & $3.2 \pm 0.4$ \\
\hline 141 & $A r^{a}$ & 6.95 & $0.00-16.89$ & 8 & $1.6 \pm 0.2$ \\
\hline 168 & $\mathrm{Ar}^{\mathbf{a}}$ & 9.01 & $0.00-25.28$ & 9 & $1.6 \pm 0.2$ \\
\hline 296 & $\mathrm{~N}_{2}{ }^{\mathbf{a}}$ & 15.15 & $1.07-20.92$ & 8 & $1.49 \pm 0.18$ \\
\hline
\end{tabular}




\begin{tabular}{|l|l|l|l|l|l|}
\hline \multirow{4}{*}{} & $\mathrm{N}_{2}{ }^{\mathbf{a}}$ & 14.30 & $0.00-27.46$ & 9 & $1.45 \pm 0.18$ \\
\cline { 2 - 6 } & $\mathrm{N}_{2}{ }^{\mathbf{a}}$ & 32.00 & $0.00-41.46$ & 9 & $1.48 \pm 0.19$ \\
\cline { 2 - 6 } $\mathrm{N}_{2}{ }^{\mathbf{b}}$ & 9.02 & $10.51-52.57$ & 5 & $1.72 \pm 0.18$ \\
\hline & $\mathrm{N}_{2}{ }^{\mathbf{b}}$ & 11.69 & $6.84-34.19$ & 5 & $1.66 \pm 0.52$ \\
\hline & & & & & $\mathbf{1 . 6} \pm \mathbf{0 . 2}$ \\
\hline
\end{tabular}

\section{Theoretical Methodology}

Electronic structure calculations were performed to optimise the stationary points for the different channels of the reaction of the $\mathrm{CN}$ radical with methanol using Gaussian09. ${ }^{58}$ Only exothermic channels were considered as viable reaction channels at such low temperatures and are shown here:

$$
\begin{aligned}
& \mathrm{CH}_{3} \mathrm{OH}+\mathrm{CN} \stackrel{R 1 a}{\longrightarrow} \mathrm{CH}_{3} \mathrm{O}+\mathrm{HCN} \quad(-86.6) \\
& \stackrel{R 1 b}{\longrightarrow} \mathrm{CH}_{3} \mathrm{O}+\mathrm{HNC} \quad(-24.5) \\
& \stackrel{R 2 a}{\longrightarrow} \mathrm{CH}_{2} \mathrm{OH}+\mathrm{HCN} \quad(-122.7) \\
& \stackrel{R 2 b}{\longrightarrow} \mathrm{CH}_{2} \mathrm{OH}+\mathrm{HNC} \quad(-60.7) \\
& \stackrel{R 3 a}{\longrightarrow} \mathrm{CH}_{3} \mathrm{CN}+\mathrm{OH} \quad(-129.2) \\
& \stackrel{R 3 b}{\longrightarrow} \mathrm{CH}_{3} \mathrm{NC}+\mathrm{OH} \quad(-28.1) \\
& \stackrel{R 4}{\longrightarrow} \mathrm{CH}_{3} \mathrm{OCN}+\mathrm{H} \quad(-6.0) \\
& \stackrel{R 5}{\longrightarrow} \mathrm{NCCH}_{2} \mathrm{OH}+\mathrm{H} \quad(-62.8) \\
& \stackrel{R 6}{\longrightarrow} \mathrm{HOCN}+\mathrm{CH}_{3} \quad(-99.5)
\end{aligned}
$$


High accuracy single point energies were calculated using $\operatorname{CCSD}(T)^{59,60} /$ aug-cc-pVTZ ${ }^{61,62}$ for all the structures (reactants and products) following optimisation of their geometries at

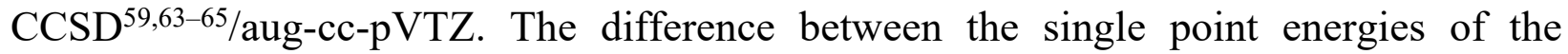
products and reactants was used to calculate the changes in energy for all the reaction channels, and are provided in parenthesis next to each channel in $\mathrm{kJ} / \mathrm{mol}$. The parameters for the optimised structures are given in the supplementary information. The standard reaction enthalpy $\Delta H_{r}^{\circ}(298.15 \mathrm{~K})$ for each channel was also calculated, as explained by Ochterski, ${ }^{66}$ using the composite CBS-QB3 ${ }^{67,68}$ method.
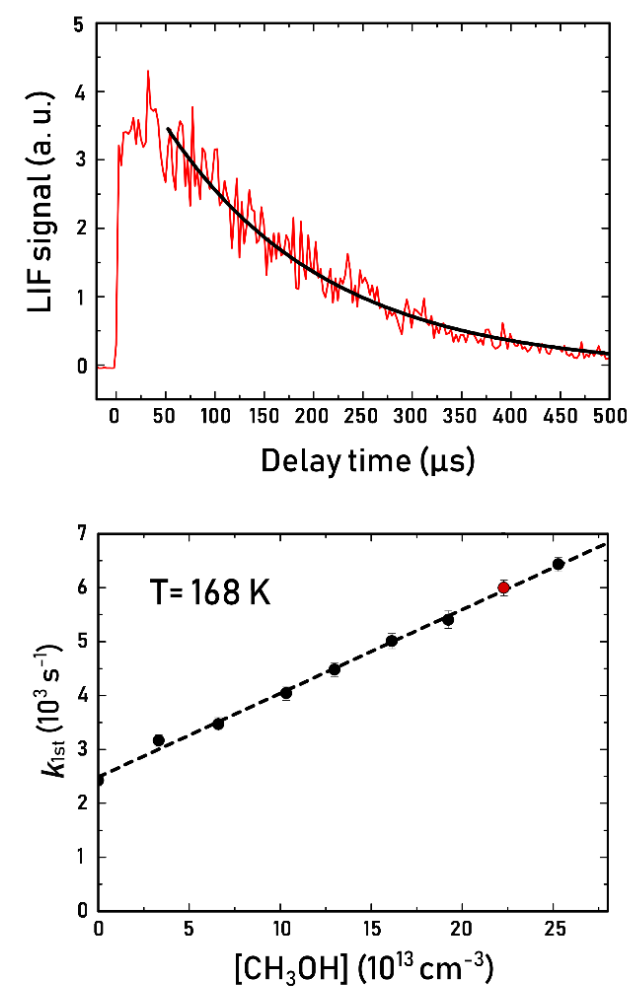

Figure 2. Typical kinetics plot obtained using PLP-LIF at a temperature of $168 \mathrm{~K}$ in continuous CRESU flow. The upper panel shows the LIF signal decay of $\mathrm{CN}\left(B^{2} \Sigma^{+} \rightarrow\right.$ $X^{2} \Sigma^{+}$) at a methanol density $2.22 \times 10^{14} \mathrm{~cm}^{-3}$ fitted to a single exponential decay function. The lower panel shows the second order plot where the pseudo-first order rate coefficients are plotted against the methanol concentration. The slopes of the second order plots yield the rate coefficients as shown in Table 1. 


\section{Results}

A typical LIF decay trace and second order plot obtained at temperature $168 \mathrm{~K}$ are shown in Figure 2. LIF measurements were also taken at negative time delays to establish a pretrigger baseline, as seen in Figure 2. The fit is only made after 10-50 $\mu$ s so as to allow enough time for rotational relaxation of $\mathrm{CN}$ and for the photomultiplier tube to recover from the excimer laser scatter. The non-zero intercept in the second order plot, shown in the lower panel of Figure 2, is due to the loss of $\mathrm{CN}$ by diffusion out of the probed beam area and by reaction with the precursor and/or impurities in the buffer gas. As the laser alignment and other external factors may change over periods of days, the intercepts of different second-order plots are not necessarily constant. Therefore, we derive the secondorder rate coefficient for each temperature from the readings taken on a given day rather than taking all of the $k_{l s t}$ values at that temperature.

The weighted means of these multiple readings are then calculated for each temperature are shown in Table 1 along with their uncertainties, calculated using 95\% confidence limits of the standard error from the two-sided Student's $t$-distribution. The experimentally measured rate coefficients over the temperature range $T=16.7-296 \mathrm{~K}$ are well fit by the modified Arrhenius equation $k(T)=1.26 \times 10^{-11}(T / 300 \mathrm{~K})^{-0.7} \exp (-5.4 \mathrm{~K} / T) \mathrm{cm}^{3} \mathrm{~s}^{-1}$ and are shown in Figure 3 along with the rate coefficients measured at room temperature from two previous studies.
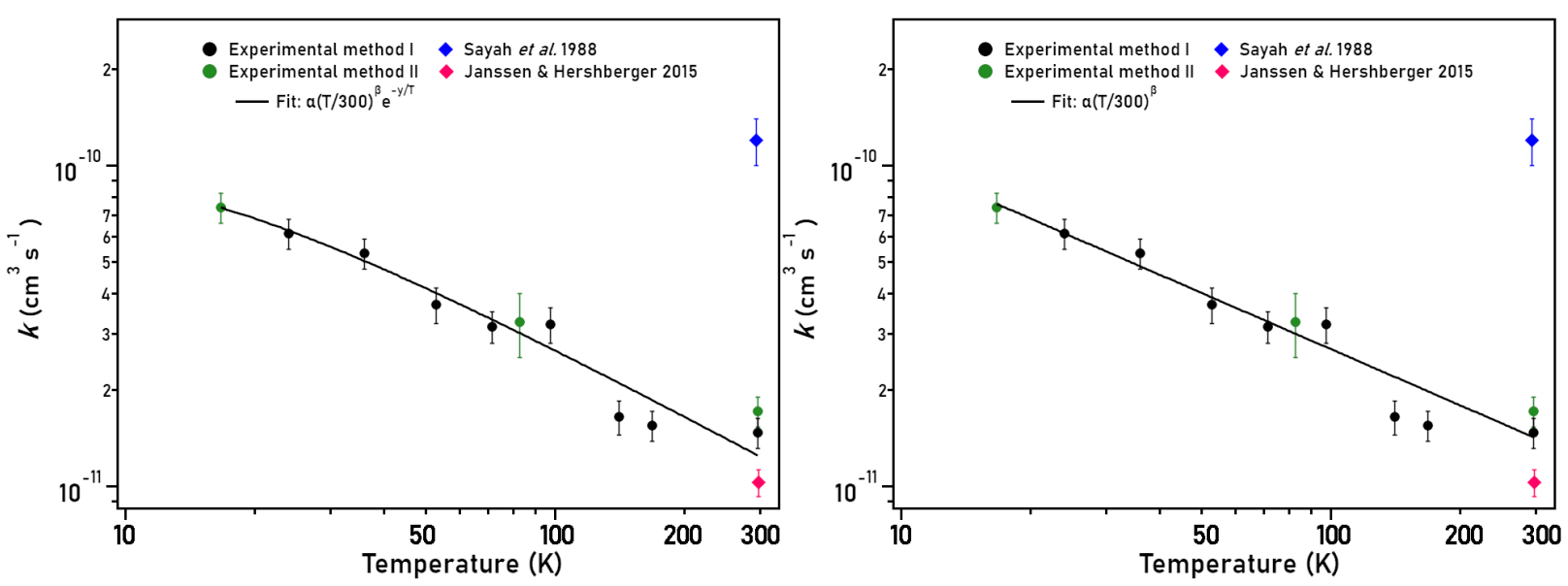
Figure 3. Rate coefficients for the reaction of the $\mathrm{CN}$ radical with methanol displayed on a log-log scale as a function of temperature. The filled black circles are the experiments performed with the CRESU setup using EM I and the filled green circles are the experiments using EM II. The blue diamond represents the work of Sayah et al. and the magenta diamond represents the work of Janssen and Hershberger. $\boldsymbol{a}$. The modified Arrhenius fit: $\alpha(T / 300 \mathrm{~K})^{\beta} \mathrm{e}^{-\gamma / T}$ with the fitting parameters $( \pm 95 \%$ confidence limits): $\alpha=(1.26 \pm 0.43) \times 10^{-11} \mathrm{~cm}^{3} \mathrm{~s}^{-1}, \beta=(-0.72 \pm 0.33)$ and $\gamma=(5.4 \pm 12) . \boldsymbol{b}$. Modified Arrhenius fit with $\gamma=0$ : $\alpha(T / 300)^{\beta}$ with the fitting parameters: $\left.\alpha=(1.42 \pm 0.31)\right) \times 10^{-11} \mathrm{~cm}^{3} \mathrm{~s}^{-1}$ and $\beta=(-0.58 \pm 0.09)$.

The upper limit for the concentration of methanol is an important experimental constraint imposed due to the formation of methanol dimers, which could interfere with the experimental measurement. The range of methanol densities used to calculate the secondorder rate coefficient for each temperature, as mentioned in Table 1, were based on the tests where first-order rate coefficients were measured against a large range of methanol density, and a careful observation of when the first order plot deviates from its linear behavior, which would indicate the loss of pseudo-first order conditions due to formation of dimers. The methanol concentration at which this deviation starts to occur is dependent on the nature of the buffer gas and its temperature and density, occurring at lower values for low temperatures and high densities.

The reaction enthalpies $\Delta H_{r}^{\circ}(298.15 \mathrm{~K})$ were obtained at CBS-QB3, which is a composite method used widely ${ }^{69-71}$ to obtain accurate energies of molecules and radicals. The values obtained were compared with enthalpy values calculated using the active thermochemical table (ATcT) $)^{72-74}$ and are shown in Table 2. ATcT has been developed by Ruscic and coworkers and is based on statistical analysis to produce a self-consistent thermochemical network. The reaction enthalpies for the various channels follow the same trend across the different methods, with channel R3a being the most exothermic, followed by R2a, R6, and R1a. 
Table 2. Reaction enthalpies $\Delta H_{r}^{\circ}(298.15 \mathrm{~K})$, in $\mathrm{kJ} / \mathrm{mol}$, calculated for each channel using CBS-QB3 compared with the enthalpy values calculated from the values provided in the Active Thermochemical Table ver. 1.22 e. $^{74}$ The reaction enthalpies for R4 and R5 could not be calculated as the species $\mathrm{CH}_{3} \mathrm{OCN}$ and $\mathrm{NCCH}_{2} \mathrm{OH}$ are missing from the thermochemical network of ATcT ver. $1.22 \mathrm{e}$

\begin{tabular}{|c|c|c|c|c|c|c|c|c|c|}
\hline & R1a & R1b & R2a & R2b & R3a & R3b & R4 & R5 & R6 \\
\hline CBS-QB3 & -90.9 & -31.2 & -126.0 & -66.3 & -127.6 & -28.1 & -23.2 & -76.6 & -111.0 \\
\hline ATcT (1.22e) & -99.3 & -36.2 & -137.5 & -74.4 & -138.4 & -35.2 & - & - & -118.4 \\
\hline
\end{tabular}

\section{Discussion}

Figure 3 shows the experimentally obtained values of the rate coefficient from this work as a function of temperature, compared with the two previous studies measured at room temperature. The CRESU results have been fit to the modified Arrhenius equation (Kooij fit) in Figure 3a, and show a dependence $k(T)=1.26 \times 10^{-11}(T / 300 \mathrm{~K})^{-0.7} \exp (-5.4 \mathrm{~K} / T)$ $\mathrm{cm}^{3} \mathrm{~s}^{-1}$. The CRESU data was also fit using the $\alpha(T / 300 \mathrm{~K})^{\beta}$ expression, which is shown in Figure 3b, and follows the curve $k(T)=1.42 \times 10^{-11}(T / 300 \mathrm{~K})^{-0.6} \mathrm{~cm}^{3} \mathrm{~s}^{-1}$. The work by Sayah et al..$^{52}$ at room temperature yielded a value of $1.2 \times 10^{-10} \mathrm{~cm}^{3} \mathrm{~s}^{-1}$, which was different from the value obtained here using EM I by an order of magnitude. Following this, a secondary method for $\mathrm{CN}$ radical generation and for creating methanol/buffer gas mixtures (EM II) was used to confirm the measurements made using EM I (particularly those at room temperature) and to reduce the likelihood of systematic errors. A room temperature rate coefficient was measured using EM II that agrees within error to that obtained using EM I. The current results are further supported by the work of Janssen and Hershberger ${ }^{53}$ who obtained a rate coefficient of $1.03 \times 10^{-11} \mathrm{~cm}^{3} \mathrm{~s}^{-1}$ at room temperature, which is in good agreement with the value reported here of $(1.6 \pm 0.2) \times 10^{-11} \mathrm{~cm}^{3} \mathrm{~s}^{-1}$. It is unclear why the value measured by Sayah et al. is faster than these three essentially independent measurements by an order of magnitude. 
The difference between the ionization potential of methanol and the electron affinity of $\mathrm{CN}$ radical is $6.98 \mathrm{eV}$, which is less than the $8.75 \mathrm{eV}$ semi-empirical limit proposed by Ian Smith and colleagues ${ }^{75}$ for the existence of a non-submerged barrier to reaction. This suggests the reaction between the $\mathrm{CN}$ radical and methanol will be rapid even at low temperatures, with a rate coefficient greater than $10^{-10} \mathrm{~cm}^{3} \mathrm{~s}^{-1}$ at $10 \mathrm{~K}$, consistent with what was observed in this study.

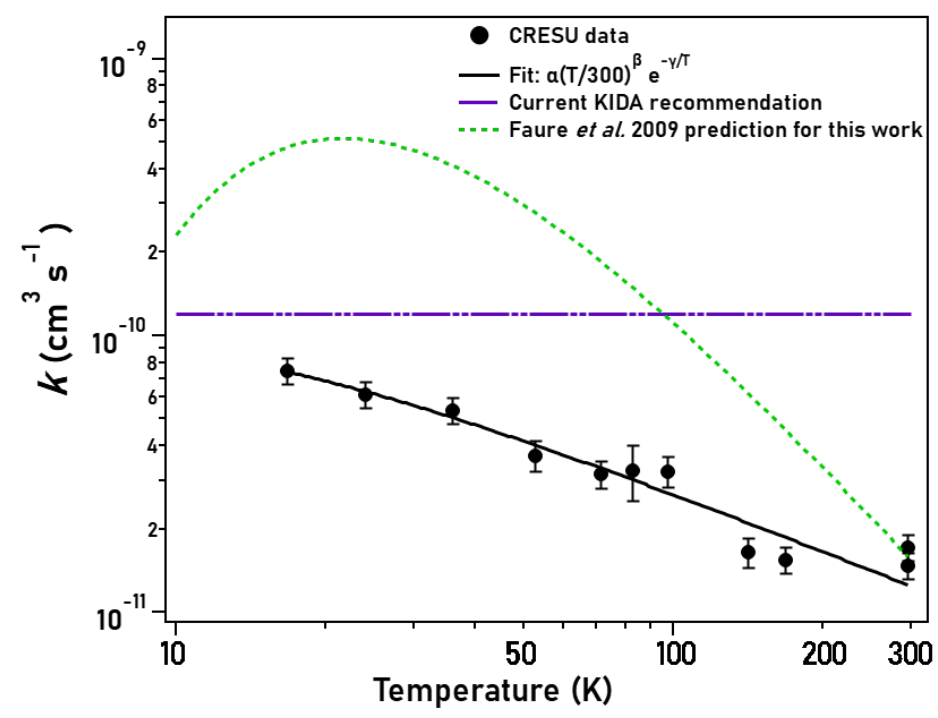

Figure 4. The CRESU experimental data (black filled circles) fit with a modified Arrhenius equation (black solid line), $k(T)=1.26 \times 10^{-11}(T / 300 \mathrm{~K})^{-0.7} \exp (-5.5 \mathrm{~K} / T) \mathrm{cm}^{3} \mathrm{~s}^{-1}$, and the prediction, $k(\mathrm{~T})=1.80 \times 10^{-11}(T / 300 \mathrm{~K})^{-2.1} \exp (-44.6 \mathrm{~K} / T) \mathrm{cm}^{3} \mathrm{~s}^{-1}$, based on the room temperature value from this work using capture theory model from Faure et al. ${ }^{76}$ (green dashed line). The current KIDA recommendation for this reaction is shown in purple.

Faure et al. ${ }^{76}$ provided a semiempirical model which combines room temperature kinetics data with a long-range capture method to predict rate coefficients for neutral-neutral reactions at low temperature. For reactions with rate coefficients greater than $10^{-11} \mathrm{~cm}^{3} \mathrm{~s}^{-1}$ at room temperature, a fit $\left(k(\mathrm{~T})=\alpha(T / 300 \mathrm{~K})^{\beta} \mathrm{e}^{-\gamma / T}\right)$ is proposed to be valid at temperatures as low as $5 \mathrm{~K}$. A plot obtained using the model is shown in Figure 4. The method, along with the parameters used are provided in Table S1 and Table S2 of Supplementary 
information. This method, however, over-predicts the rate coefficient, suggesting that the reaction is not controlled by long-range attractive forces even at the lowest temperatures where measurements have been performed. It appears likely that submerged barriers are playing an important role in determining the low temperature reactivity.

The reaction enthalpies $\Delta H_{r}^{\circ}(298.15 \mathrm{~K})$ obtained using CBS-QB3 and ATcT, shown in Table 2, show a reasonable agreement. The reaction enthalpies for R4 and R5 could not be calculated from ATcT due to missing values for $\mathrm{NCCH}_{2} \mathrm{OH}$ and $\mathrm{CH}_{3} \mathrm{OCN}$ in the active thermochemical table. The reaction channels R1a, R2a, R3a and R6 are the most thermodynamically favored product channels of the studied reaction. Similar trends were also found from the reaction energies calculated using the difference between the single point $\operatorname{CCSD}(\mathrm{T})$ /aug-cc-pVTZ) energies of the reactants and products. The HNC channels for both R1 and R2 were found to have lower stabilization energies compared to the $\mathrm{HCN}$ analogues, which is expected as HCN is more stable than HNC. Preliminary calculations performed at B3LYP/aug-cc-pVTZ to identify the saddle points for the reaction channels, suggest that the channels R3a, R3b, and R4 have very high (zero-point corrected) barriers of $83.6 \mathrm{~kJ} \mathrm{~mol}^{-1}, 134.7 \mathrm{~kJ} \mathrm{~mol}^{-1}$ and $227.9 \mathrm{~kJ} \mathrm{~mol}^{-1}$, respectively, making them unlikely to take place in low temperature environments. These preliminary calculations were likely of an insufficiently high level to locate the submerged saddle points for the reaction channels $\mathrm{R} 1$ and R2, indicating the need for more accurate ab-initio methods.

To the best of authors' knowledge, this is the first set of kinetics data published for this reaction at low temperatures, which makes it useful for atmospheric and astrochemical models. The Kinetics Database for Astrochemistry, KIDA, (Homepage http://kida.obs.ubordeaux1.fr/ accessed July 2019), ${ }^{77,78}$ currently uses the rate coefficient measured by Sayah et al. over the whole temperature range of $10-300 \mathrm{~K}$, which is significantly different from what is observed experimentally both here and by Janssen and Hershberger. ${ }^{53}$ Furthermore, the reaction is assumed to proceed in equal ratios via channels $1 \mathrm{a}\left(\mathrm{CH}_{3} \mathrm{O}+\right.$ $\mathrm{HCN})$ and $2 \mathrm{a}\left(\mathrm{CH}_{2} \mathrm{OH}+\mathrm{HCN}\right)$. Janssen and Hershberger measured the $\mathrm{CH}_{2} \mathrm{OH}$ channel as the dominant reaction product at room temperature, with only $8 \%$ into the methoxy 
channel, based on isotopic experiments. Models using the room temperature rate coefficient reported in KIDA, therefore, overpredict both the rate of $\mathrm{CH}_{3} \mathrm{O}$ formation and its yield relative to the $\mathrm{CH}_{2} \mathrm{OH}$ isomer. The product branching ratios for this reaction have not been measured below room temperature, so it is unknown whether the reaction will be a significant source of methoxy under dense cloud conditions.

A new technique combining Chirped-Pulse Fourier-Transform Microwave (CP-FTMW) spectroscopy with CRESU flows, named Chirped-Pulse in Uniform supersonic Flow (CPUF), has been used to measure the channel-specific rate coefficients at low temperature. ${ }^{79}$ This technique can aid in understanding which reaction channels may be dominant at low temperatures. An E-band ( $60-90 \mathrm{GHz})$ spectrometer has been developed in Rennes that will allow the investigation of the products formed in the reaction between the $\mathrm{CN}$ radical and methanol as some rotational lines corresponding to $\mathrm{CH}_{3} \mathrm{O}$ and $\mathrm{CH}_{2} \mathrm{OH}$ fall within this frequency range.

Other destruction routes for methanol with the $\mathrm{OH}$ radical ${ }^{36}$ and the $\mathrm{C}\left({ }^{3} \mathrm{P}\right)^{42}$ radical have been reported to have rate coefficients approaching $10^{-10} \mathrm{~cm}^{3} \mathrm{~s}^{-1}$ at $10 \mathrm{~K}$. A similar rate coefficient for the reaction of $\mathrm{CN}$ with methanol further establishes the role of this reaction as a significant destruction route for methanol in cold interstellar clouds where both these species have been detected. The room temperature rate coefficient reported here is an order of magnitude lower than the current value in KIDA, suggesting that astrochemical networks involving warm gas temperatures (e.g., hot cores models) may overpredict the destruction of methanol. Use of the current KIDA-recommended rate coefficients may also lead to overprediction of the abundance of the methoxy radical, which is thought to be a precursor to more complex organic molecules like dimethyl ether and methyl formate. ${ }^{6}$ Astrochemical models assuming the current KIDA rate coefficients $\left(6.0 \times 10^{-11} \mathrm{~cm}^{3} \mathrm{~s}^{-1}\right.$ into both the $\mathrm{CH}_{3} \mathrm{O}$ and $\mathrm{CH}_{2} \mathrm{OH}$ channels) should be updated to reflect these new laboratory data. Janssen and Hershberger's ${ }^{53}$ room temperature branching ratio should be used at $T<$ $300 \mathrm{~K}$ until low temperature measurements have been made. 


\section{Conclusion and future outlook}

The CRESU technique coupled with PLP-LIF has been employed to show that the reaction between the $\mathrm{CN}$ radical and methanol has a negative temperature dependence in the temperature range $16.7-296 \mathrm{~K}$, well-characterized by the modified Arrhenius equation $k(T)=1.29 \times 10^{-11}(T / 300 \mathrm{~K})^{-0.7} \exp (-5.5 \mathrm{~K} / T)$. The present measurements vary significantly from the room temperature value of Sayah et. al. which is currently the value recommended by the KIDA database for all temperatures between 10 and $300 \mathrm{~K}$. While this experiment has yielded the overall rate coefficient for the reaction of the $\mathrm{CN}$ radical with methanol, the PLP-LIF technique is unable to provide product-specific rate coefficients or branching ratios. Electronic structure calculations revealed that the reaction channels involving $\mathrm{CN}$ substitution have high barriers, making them unlikely to occur at low temperatures. The $\mathrm{H}$ atom abstraction routes are likely to be the dominant reaction channels under cold ISM conditions, forming the isomers $\mathrm{CH}_{2} \mathrm{OH}$ and $\mathrm{CH}_{3} \mathrm{O}$. More calculations are needed to locate the submerged saddle points for other channels for the reaction of the $\mathrm{CN}$ radical with methanol, followed by theoretical kinetics calculations. A new setup integrating chirped-pulse broadband microwave spectroscopy with continuous flow CRESU is being developed in Rennes and will allow the identification of the products and provide the branching ratios for the reaction channels at low temperatures.

\section{Supporting Information}

The parameters and a description of the method suggested by Faure et al. ${ }^{76}$ which extrapolates the room temperature rate coefficient to lower temperatures based on longrange capture model are provided in the supplementary information. The Cartesian coordinates of the optimized geometries for various suggested reaction channels are also provided. 


\section{Acknowledgements}

The authors would like to thank Hamza Labiad and Joey Messinger for assistance with experiments, and Jonathan Courbe, Jonathan Thiévin, Didier Biet, Ewen Gallou, and Alexandre Dapp for technical support. The authors acknowledge funding from the European Research Council (ERC) under the European Union's Horizon 2020 research and innovation programme under grant agreement 695724-CRESUCHIRP. The authors are also grateful for support from the European Regional Development Fund, the Region of Brittany and Rennes Metropole. This work was supported by the CNRS/CNES programme "Physique et Chimie du Milieu Interstellaire" (PCMI). 


\section{References}

(1) Herbst, E.; van Dishoeck, E. F. Complex Organic Interstellar Molecules. Annu. Rev. Astron. Astrophys. 2009, 47 (1), 427-480. https://doi.org/10.1146/annurevastro-082708-101654.

(2) Garrod, R. T.; Weaver, S. L. W.; Herbst, E. Complex Chemistry in Star-forming Regions: An Expanded Gas-Grain Warm-up Chemical Model. Astrophys. J. 2008, 682, 283-302. https://doi.org/10.1086/588035.

(3) Caselli, P.; Hasegawa, T. I.; Herbst, E. Chemical Differentiation between StarForming Regions - The Orion Hot Core and Compact Ridge. Astrophys. J. 1993, 408, 548-558. https://doi.org/10.1086/172612.

(4) Burke, D. J.; Puletti, F.; Woods, P. M.; Viti, S.; Slater, B.; Brown, W. A. Trapping and Desorption of Complex Organic Molecules in Water at 20 K. J. Chem. Phys. 2015, 143, 164704. https://doi.org/10.1063/1.4934264.

(5) Vasyunin, A. I.; Herbst, E. Reactive Desorption and Radiative Association as Possible Drivers of Complex Molecule Formation in the Cold Interstellar Medium. Astrophys. J. 2013, 769 (1), 34. https://doi.org/10.1088/0004-637X/769/1/34.

(6) Balucani, N.; Ceccarelli, C.; Taquet, V. Formation of Complex Organic Molecules in Cold Objects: The Role of Gas-Phase Reactions. Mon. Not. R. Astron. Soc. Lett. 2015, 449 (1), L16-L20. https://doi.org/10.1093/mnrasl/slv009.

(7) Bacmann, A.; Taquet, V.; Faure, A.; Kahane, C.; Ceccarelli, C. Detection of Complex Organic Molecules in a Prestellar Core: A New Challenge for Astrochemical Models. Astron. Astrophys. 2012, 541, L12. https://doi.org/10.1051/0004-6361/201219207.

(8) Sims, I. R.; Queffelec, J. L.; Travers, D.; Rowe, B. R.; Herbert, L. B.; Karthäuser, 
J.; Smith, I. W. M. Rate Constants for the Reactions of CN with Hydrocarbons at Low and Ultra-Low Temperatures. Chem. Phys. Lett. 1993, 211 (4-5), 461-468. https://doi.org/10.1016/0009-2614(93)87091-G.

(9) Balucani, N.; Asvany, O.; Huang, L. C. L.; Lee, Y. T.; Kaiser, R. I.; Osamura, Y.; Bettinger, H. F. Formation of Nitriles in the Interstellar Medium via Reactions of Cyano Radicals, $\mathrm{CN}\left(\mathrm{X}^{2} \Sigma^{+}\right.$, with Unsaturated Hydrocarbons. Astrophys. J. 2002, 545 (2), 892-906. https://doi.org/10.1086/317848.

(10) Sabbah, H.; Biennier, L.; Sims, I. R.; Georgievskii, Y.; Klippenstein, S. J.; Smith, I. W. M. Understanding Reactivity at Very Low Temperatures: The Reactions of Oxygen Atoms with Alkenes. Science. 2007, 317 (5834), 102-105. https://doi.org/10.1126/science.1142373.

(11) Morales, S. B.; Bennett, C. J.; Le Picard, S. D.; Canosa, A.; Sims, I. R.; Sun, B. J.; Chen, P. H.; Chang, A. H. H.; Kislov, V. V.; Mebel, A. M.; et al. A Crossed Molecular Beam, Low-Temperature Kinetics, and Theoretical Investigation of the Reaction of the Cyano Radical $(\mathrm{CN})$ with 1,3-Butadiene $\left(\mathrm{C}_{4} \mathrm{H}_{6}\right)$. A Route to Complex Nitrogen-Bearing Molecules in Low-Temperature Extraterrastrial . Astrophys. J. 2011, 742 (1), 26. https://doi.org/10.1088/0004-637X/742/1/26.

(12) Shannon, R. J.; Blitz, M. A.; Goddard, A.; Heard, D. E. Accelerated Chemistry in the Reaction between the Hydroxyl Radical and Methanol at Interstellar Temperatures Facilitated by Tunnelling. Nat. Chem. 2013, 5, 745-749. https://doi.org/10.1038/nchem.1692.

(13) Millar, T. J.; Herbst, E.; Charnley, S. B. The Formation of Oxygen-Containing Organic Molecules in the Orion Compact Ridge. Astrophys. J. 1991, 369, 147-156. https://doi.org/10.1086/169745.

(14) Ball, J. A.; Gottlieb, C. A.; Lilley, A. E.; Radford, H. E. Detection of Methyl Alcohol in Sagittarius. Astrophys. J. 1970, 162, L203-L210. https://doi.org/10.1086/180654. 
(15) Batrla, W.; Matthewst, H. E.; Menten, K. M.; Walmsley, C. M. Detection of Strong Methanol Masers towards Galactic H II Regions. Nature 1987, 326, 49-51. https://doi.org/https://doi.org/10.1038/326049a0.

(16) Vastel, C.; Ceccarelli, C.; Lefloch, B.; Bachiller, R. The Origin of Complex Organic Molecules in Prestellar Cores. Astrophys. J. Lett. 2014, 795 (1), 6-11. https://doi.org/10.1088/2041-8205/795/1/L2.

(17) Bizzocchi, L.; Caselli, P.; Spezzano, S.; Leonardo, E. Deuterated Methanol in the Pre-Stellar Core L1544. Astron. Astrophys. 2014, 569, A27. https://doi.org/10.1051/0004-6361/201423858.

(18) Turner, B. E. The Physics and Chemistry of Small Translucent Molecular Clouds. XI. Methanol. Astrophys. J. 1998, 501 (2), 731-748. https://doi.org/10.1086/305859.

(19) van Dishoeck, E. F.; Blake, G. A.; Jansen, D. J.; Groesback, T. D. Molecular Abundances and Low-Mass Star Formation. II. Organic and Deuterated Species toward IRAS 16293-2422. Astrophys. J. 1995, 447 (2), 760-782. https://doi.org/10.1086/175915.

(20) Kristensen, L. E.; van Dishoeck, E. F.; van Kempen, T. a.; Cuppen, H. M.; Brinch, C.; Jørgensen, J. K.; Hogerheijde, M. R. Methanol Maps of Low-Mass Protostellar Systems: The Serpens Molecular Core. Astron. Astrophys. 2010, 516, 16. https://doi.org/10.1051/0004-6361/201014182.

(21) Walsh, C.; Loomis, R. A.; Öberg, K. I.; Kama, M.; van 't Hoff, M. L. R.; Millar, T. J.; Aikawa, Y.; Herbst, E.; Widicus Weaver, S. L.; Nomura, H. First Detection of Gas-Phase Methanol in a Protoplanetary Disk. Astrophys. J. Lett. 2016, 823 (1), L10. https://doi.org/10.3847/2041-8205/823/1/110.

(22) Biver, N.; Bockelée-Morvan, D.; Crovisier, J.; Henry, F.; Davies, J. K.; Matthews, H. E.; Colom, P.; Gerard, E.; Lis, D. C.; Phillips, T. G.; et al. Spectroscopic 
Observations of Comet C/1999 H1 (Lee) with the SEST, JCMT, CSO, IRAM, and Nançay Radio Telescopes'. Astron. J. 2000, 120, 1554-1570.

https://doi.org/10.1086/301529.

(23) Biver, N.; Bockelée-Morvan, D.; Crovisier, J.; Colom, P.; Henry, F.; Moreno, R.; Paubert, G.; Despois, D.; Lis, D. C. Chemical Composition Diversity among 24 Comets Observed at Radio Wavelengths. Earth, Moon Planets 2002, 90 (1-4), 323-333. https://doi.org/10.1023/A:1021530316352.

(24) Wollenhaupt, M.; Carl, S. A.; Horowitz, A.; Crowley, J. N. Rate Coefficients for Reaction of $\mathrm{OH}$ with Acetone between 202 and 395 K. J. Phys. Chem. A 2000, 104 (12), 2695-2705. https://doi.org/10.1021/jp993738f.

(25) Dillon, T. J.; Hölscher, D.; Sivakumaran, V.; Horowitz, A.; Crowley, J. N. Kinetics of the Reactions of HO with Methanol (210-351 K) and with Ethanol (216-368 K). Phys. Chem. Chem. Phys. 2005, 7, 349-355. https://doi.org/10.1039/b413961e.

(26) Rowe, B. R.; Dupeyrat, G.; Marquette, J. B.; Gaucherel, P. Study of the Reactions $\mathrm{N}_{2}^{+}+2 \mathrm{~N}_{2} \rightarrow \mathrm{N}_{4}^{+}+\mathrm{N}_{2}$ and $\mathrm{O}_{2}^{+}+2 \mathrm{O}_{2} \rightarrow \mathrm{O}_{4}^{+}+\mathrm{O}_{2}$ from 20 to $160 \mathrm{~K}$ by the CRESU Technique. J. Chem. Phys. 1984, 80 (10), 4915-4921. https://doi.org/10.1063/1.446513.

(27) Rowe, B. R.; Marquette, J. B.; Dupeyrat, G.; Ferguson, E. E. Reactions of $\mathrm{He}^{+}$and $\mathrm{N}^{+}$Ions with Several Molecules at 8 K. Chem. Phys. Lett. 1985, 113 (4), 403-406. https://doi.org/10.1016/0009-2614(85)80391-2.

(28) Marquette, J. B.; Rowe, B. R.; Dupeyrat, G.; Poissant, G.; Rebrion, C. Ion-PolarMolecule Reactions: A CRESU Study of $\mathrm{He}^{+}, \mathrm{C}^{+}, \mathrm{N}^{+}+\mathrm{H}_{2} \mathrm{O}, \mathrm{NH}_{3}$ at 27, 68 and 163 K. Chem. Phys. Lett. 1985, 122 (5), 431-435. https://doi.org/10.1016/00092614(85)87241-9.

(29) Rowe, B. R.; Canosa, A.; Le Page, V. FALP and CRESU Studies of Ionic Reactions. Int. J. Mass Spectrom. Ion Process. 1995, 149-150, 573-596. 
https://doi.org/10.1016/0168-1176(95)04292-S.

(30) Speck, T.; Mostefaoui, T. I.; Travers, D.; Rowe, B. R. Pulsed Injection of Ions into the CRESU Experiment. Int. J. Mass Spectrom. 2001, 208 (1-3), 73-80. https://doi.org/10.1016/S1387-3806(01)00383-9.

(31) Joalland, B.; Jamal-Eddine, N.; Kłos, J.; Lique, F.; Trolez, Y.; Guillemin, J. C.; Carles, S.; Biennier, L. Low-Temperature Reactivity of $\mathrm{C}_{2 \mathrm{n}+1} \mathrm{~N}^{-}$Anions with Polar Molecules. J. Phys. Chem. Lett. 2016, 7 (15), 2957-2961. https://doi.org/10.1021/acs.jpclett.6b01191.

(32) Carty, D.; Le Page, V.; Sims, I. R.; Smith, I. W. M. Low Temperature Rate Coefficients for the Reactions of $\mathrm{CN}$ and $\mathrm{C}_{2} \mathrm{H}$ Radicals with Allene $\left(\mathrm{CH}_{2}=\mathrm{C}=\mathrm{CH}_{2}\right)$ and Methyl Acetylene ( $\left.\mathrm{CH}_{3} \mathrm{CCH}\right)$. Chem. Phys. Lett. 2001, 344 (s 3-4), 310-316. https://doi.org/10.1016/S0009-2614(01)00682-0.

(33) Mullen, C.; Smith, M. A. Low Temperature $\mathrm{NH}\left(\mathrm{X}^{3} \Sigma^{-}\right)$Radical Reactions with NO, Saturated, and Unsaturated Hydrocarbons Studied in a Pulsed Supersonic Laval Nozzle Flow Reactor between 53 and 188 K. J. Phys. Chem. A 2005, 109 (7), 1391-1399. https://doi.org/10.1021/jp045541f.

(34) Daugey, N.; Caubet, P.; Bergeat, A.; Costes, M.; Hickson, K. M. Reaction Kinetics to Low Temperatures. Dicarbon + Acetylene, Methylacetylene, Allene and Propene from $77 \leq \mathrm{T} \leq 296$ K. Phys. Chem. Chem. Phys. 2008, 10, 729-737. https://doi.org/10.1039/b710796j.

(35) Cheikh Sid Ely, S.; Morales, S. B.; Guillemin, J. C.; Klippenstein, S. J.; Sims, I. R. Low Temperature Rate Coefficients for the Reaction $\mathrm{CN}+\mathrm{HC}_{3} \mathrm{~N}$. J. Phys. Chem. $A$ 2013, 117 (46), 12155-12164. https://doi.org/10.1021/jp406842q.

(36) Ocaña, A. J.; Blázquez, S.; Potapov, A.; Ballesteros, B.; Canosa, A.; Antiñolo, M.; Vereecken, L.; Albaladejo, J.; Jiménez, E. Gas-Phase Reactivity of $\mathrm{CH}_{3} \mathrm{OH}$ toward $\mathrm{OH}$ at Interstellar Temperatures (11.7-177.5 K): Experimental and Theoretical 
Study. Phys. Chem. Chem. Phys. 2019, 21, 6942-6957.

https://doi.org/10.1039/c9cp00439d.

(37) James, P. L.; Sims, I. R.; Smith, I. W. M.; Alexander, M. H.; Yang, M. A Combined Experimental and Theoretical Study of Rotational Energy Transfer in Collisions between $\mathrm{NO}\left(\mathrm{X}^{2} \Pi_{1 / 2}, \mathrm{~V}=3, \mathrm{~J}\right)$ and $\mathrm{He}, \mathrm{Ar}$ and $\mathrm{N}_{2}$ at Temperatures down to 7 K. J. Chem. Phys. 1998, 109 (10), 3882-3897. https://doi.org/10.1063/1.476517.

(38) Carty, D.; Goddard, A.; Sims, I. R.; Smith, I. W. M. Rotational Energy Transfer in Collisions between $\mathrm{CO}\left(\mathrm{X}^{1} \Sigma^{+}, \mathrm{V}=2, \mathrm{~J}=0,1,4\right.$, and 6) and $\mathrm{He}$ at Temperatures from 294 to 15 K. J. Chem. Phys. 2004, 121 (10), 4671-4683. https://doi.org/10.1063/1.1780163.

(39) Sánchez-González, R.; Eveland, W. D.; West, N. A.; Mai, C. L. N.; Bowersox, R. D. W.; North, S. W. Low Temperature Collisional Quenching of $\mathrm{NO} \mathrm{A}^{2} \Sigma^{+}\left(\mathrm{v}^{\prime}=0\right)$ by $\mathrm{NO}\left(\mathrm{X}^{2} \Pi\right)$ and $\mathrm{O} 2$ between 34 and 109 K. J. Chem. Phys. 2014, 141 (7), 074313. https://doi.org/10.1063/1.4892980.

(40) Mertens, L. A.; Labiad, H.; Denis-Alpizar, O.; Fournier, M.; Carty, D.; Le Picard, S. D.; Stoecklin, T.; Sims, I. R. Rotational Energy Transfer in Collisions between $\mathrm{CO}$ and $\mathrm{Ar}$ at Temperatures from 293 to 30 K. Chem. Phys. Lett. 2017, 683 (1), 521-528. https://doi.org/10.1016/j.cplett.2017.05.052.

(41) Cooke, I. R.; Sims, I. R. Experimental Studies of Gas-Phase Reactivity in Relation to Complex Organic Molecules in Star-Forming Regions. ACS Earth Sp. Chem. 2019, 3 (7), 1109-1134. https://doi.org/10.1021/acsearthspacechem.9b00064.

(42) Shannon, R. J.; Cossou, C.; Loison, J. C.; Caubet, P.; Balucani, N.; Seakins, P. W.; Wakelam, V.; Hickson, K. M. The Fast $\mathrm{C}\left({ }^{3} \mathrm{P}\right)+\mathrm{CH}_{3} \mathrm{OH}$ Reaction as an Efficient Loss Process for Gas-Phase Interstellar Methanol. RSC Adv. 2014, 4 (50), 2634226353. https://doi.org/10.1039/c4ra03036b.

(43) Jefferts, K. B.; Penzias, A. A.; Wilson, R. W. Observation of the CN Radical in the 
Orion Nebula and W51. Astrophys. J. 1970, 161, L87-L89. https://doi.org/10.1086/180576.

(44) Henkel, C.; Schilke, P.; Mauersberger, R. Molecules in External Galaxies - The Detection of $\mathrm{CN}, \mathrm{C}_{2} \mathrm{H}$, and $\mathrm{HNC}$, and the Tentative Detection of $\mathrm{HC}_{3} \mathrm{~N}$. Astron. Astrophys. 1988, 201 (1), L23-L26.

(45) Dutrey, A.; Guilloteau, S.; Gu, M. Chemistry of Protosolar-like Nebulae: The Molecular Content of the DMTau and GGTau Disks. Astron. Astrophys. 1997, 317, L55-L58.

(46) Hily-Blant, P.; Walmsley, M.; Pineau des Forêts, G.; Flower, D. CN in Prestellar Cores. Astron. Astrophys. 2008, 480 (1), L5-L8. https://doi.org/10.1051/00046361:20079296.

(47) Wilson, E. H.; Atreya, S. K. Chemical Sources of Haze Formation in Titan's Atmosphere. Planet. Space Sci. 2003, 51 (14-15), 1017-1033. https://doi.org/10.1016/j.pss.2003.06.003.

(48) Vuitton, V.; Yelle, R. V.; McEwan, M. J. Ion Chemistry and N-Containing Molecules in Titan's Upper Atmosphere. Icarus 2007, 191 (2), 722-742. https://doi.org/10.1016/j.icarus.2007.06.023.

(49) Gautier, T.; Carrasco, N.; Buch, A.; Szopa, C.; Sciamma-O’Brien, E.; Cernogora, G. Nitrile Gas Chemistry in Titan's Atmosphere. Icarus 2011, 213 (2), 625-635. https://doi.org/10.1016/j.icarus.2011.04.005.

(50) Cernicharo, J.; Marcelino, N.; Roueff, E.; Gerin, M.; Jiménez-Escobar, A.; Muñoz Caro, G. M. Discovery of the Methoxy Radical, $\mathrm{CH}_{3} \mathrm{O}$, toward B1: Dust Grain and Gas-Phase Chemistry in Cold Dark Clouds. Astrophys. J. Lett. 2012, 759, L43. https://doi.org/10.1088/2041-8205/759/2/L43.

(51) Antiñolo, M.; Agúndez, M.; Jiménez, E.; Ballesteros, B.; Canosa, A.; Dib, G. El; Albaladejo, J.; Cernicharo, J. Reactivity of $\mathrm{OH}$ and $\mathrm{CH}_{3} \mathrm{OH}$ between 22 and $64 \mathrm{~K}$ : 
Modeling the Gas Phase Production of $\mathrm{CH}_{3} \mathrm{O}$ in Barnard 1b. Astrophys. J. 2016, 823 (1), 25. https://doi.org/10.3847/0004-637X/823/1/25.

(52) Sayah, N.; Li, X.; Caballero, J. F.; Jackson, W. M. Laser Induced Fluorescence Studies of CN Reactions with Alkanes, Alkenes and Substituted Aliphatic Species. J. Photochem. Photobiol. A Chem. 1988, 45 (2), 177-194. https://doi.org/10.1016/1010-6030(88)80127-8.

(53) Janssen, E.; Hershberger, J. F. Reaction Kinetics of the CN Radical with Primary Alcohols. Chem. Phys. Lett. 2015, 625, 26-29. https://doi.org/10.1016/j.cplett.2015.02.022.

(54) Sims, I. R.; Queffelec, J. L.; Defrance, A.; Rebrion-Rowe, C.; Travers, D.; Bocherel, P.; Rowe, B. R.; Smith, I. W. M. Ultralow Temperature Kinetics of Neutral-Neutral Reactions. The Technique and Results for the Reactions $\mathrm{CN}+\mathrm{O}_{2}$ down to $13 \mathrm{~K}$ and $\mathrm{CN}+\mathrm{NH}_{3}$ down to 25 K. J. Chem. Phys. 1994, 100 (6), 42294241. https://doi.org/10.1063/1.467227.

(55) O'Halloran, M. A.; Joswig, H.; Zare, R. N. Alignment of CN from 248 Nm Photolysis of ICN: A New Model of the Ã Continuum Dissociation Dynamics. $J$. Chem. Phys. 1987, 87 (1), 303-313. https://doi.org/10.1063/1.453627.

(56) Myer, J. A.; Samson, J. A. R. Vacuum-Ultraviolet Absorption Cross Sections of CO, HCl, and ICN between 1050 and 2100 Å. J. Chem. Phys. 1970, 52 (1), 266271. https://doi.org/10.1063/1.1672676.

(57) Felps, W. S.; Rupnik, K.; McGlynn, S. P. Electronic Spectroscopy of the Cyanogen Halides. J. Phys. Chem. 1991, 95 (2), 639-656. https://doi.org/10.1021/j100155a028.

(58) Frisch, M. J.; Trucks, G. W.; Schlegel, H. B.; Scuseria, G. E.; Robb, M. A.; Cheeseman, J. R.; Scalmani, G.; Barone, V.; Mennucci, B.; Petersson, G. A.; et al. Gaussian 09, Revision D.01. Gaussian Inc. 2013. 
https://doi.org/10.1159/000348293.

(59) Purvis, G. D.; Bartlett, R. J. A Full Coupled-Cluster Singles and Doubles Model: The Inclusion of Disconnected Triples. J. Chem. Phys. 1982, 76, 1910-1918. https://doi.org/10.1063/1.443164.

(60) Pople, J. A.; Head-Gordon, M.; Raghavachari, K. Quadratic Configuration Interaction. A General Technique for Determining Electron Correlation Energies. J. Chem. Phys. 1987, 87, 5968-5975. https://doi.org/10.1063/1.453520.

(61) Kendall, R. A.; Dunning, T. H.; Harrison, R. J. Electron Affinities of the First-Row Atoms Revisited. Systematic Basis Sets and Wave Functions. J. Chem. Phys. 1992, 96, 6796-6806. https://doi.org/10.1063/1.462569.

(62) Woon, D. E.; Dunning, T. H. Gaussian Basis Sets for Use in Correlated Molecular Calculations. III. The Atoms Aluminum through Argon. J. Chem. Phys. 1993, 98, 1358-1371. https://doi.org/10.1063/1.464303.

(63) Cizek, J. Use of the Cluster Expansion and the Technique of Diagrams in Calculations of Correlation Effects in Atoms and Molecules. In Advances in Chemical Physics; 1969; pp 35-89.

(64) Scuseria, G. E.; Janssen, C. L.; Schaefer, H. F. An Efficient Reformulation of the Closed-Shell Coupled Cluster Single and Double Excitation (CCSD) Equations. $J$. Chem. Phys. 1988, 89, 7382-7387. https://doi.org/10.1063/1.455269.

(65) Scuseria, G. E.; Schaefer, H. F. Is Coupled Cluster Singles and Doubles (CCSD) More Computationally Intensive than Quadratic Configuration Interaction (QCISD)? J. Chem. Phys. 1989, 90, 3700-3703. https://doi.org/10.1063/1.455827.

(66) Ochterski, J. W. Thermochemistry in Gaussian. Gaussian Inc Pittsburgh PA 2000. https://doi.org/10.1016/j.ijms.2007.04.005.

(67) Montgomery, J. A.; Frisch, M. J.; Ochterski, J. W.; Petersson, G. A. A Complete Basis Set Model Chemistry. VI. Use of Density Functional Geometries and 
Frequencies. J. Chem. Phys. 1999, 110, 2822-2827.

https://doi.org/10.1063/1.477924.

(68) Montgomery, J. A.; Frisch, M. J.; Ochterski, J. W.; Petersson, G. A. A Complete Basis Set Model Chemistry. VII. Use of the Minimum Population Localization Method. J. Chem. Phys. 2000, 112, 6532-6542. https://doi.org/10.1063/1.481224.

(69) Ess, D. H.; Houk, K. N. Activation Energies of Pericyclic Reactions: Performance of DFT, MP2, and CBS-QB3 Methods for the Prediction of Activation Barriers and Reaction Energetics of 1,3-Dipolar Cycloadditions, and Revised Activation Enthalpies for a Standard Set of Hydrocarbon. J. Phys. Chem. A 2005, 109 (42), 9542-9553. https://doi.org/10.1021/jp052504v.

(70) Somers, K. P.; Simmie, J. M. Benchmarking Compound Methods (CBS-QB3, CBS-APNO, G3, G4, W1BD) against the Active Thermochemical Tables: Formation Enthalpies of Radicals. J. Phys. Chem. A 2015, 119 (33), 8922-8933. https://doi.org/10.1021/acs.jpca.5b05448.

(71) Guner, V.; Khuong, K. S.; Leach, A. G.; Lee, P. S.; Bartberger, M. D.; Houk, K. N. A Standard Set of Pericyclic Reactions of Hydrocarbons for the Benchmarking of Computational Methods: The Performance of Ab Initio, Density Functional, CASSCF, CASPT2, and CBS-QB3 Methods for the Prediction of Activation Barriers, Reaction Energetics, And. J. Phys. Chem. A 2003, 107 (51), 1144511459. https://doi.org/10.1021/jp035501w.

(72) Ruscic, B.; Pinzon, R. E.; Morton, M. L.; Von Laszevski, G.; Bittner, S. J.; Nijsure, S. G.; Amin, K. A.; Minkoff, M.; Wagner, A. F. Introduction to Active Thermochemical Tables: Several "Key" Enthalpies of Formation Revisited. $J$. Phys. Chem. A 2004, 108 (45), 9979-9997. https://doi.org/10.1021/jp047912y.

(73) Ruscic, B.; Pinzon, R. E.; Von Laszewski, G.; Kodeboyina, D.; Burcat, A.; Leahy, D.; Montoy, D.; Wagner, A. F. Active Thermochemical Tables: Thermochemistry for the 21st Century. In Journal of Physics: Conference Series; 2005. 
https://doi.org/10.1088/1742-6596/16/1/078.

(74) Ruscic, B.; Bross, D. H. Active Thermochemical Tables (ATcT) values based on ver. 1.122e of the Thermochemical Network, Argonne National Laboratory (2019); available at ATcT.anl.gov.

(75) Smith, I. W. M.; Sage, A. M.; Donahue, N. M.; Herbst, E.; Quan, D. The Temperature-Dependence of Rapid Low Temperature Reactions: Experiment, Understanding and Prediction. Faraday Discuss. 2006, 133, 137-156. https://doi.org/10.1039/b600721j.

(76) Faure, A.; Vuitton, V.; Thissen, R.; Wiesenfeld, L. A Semiempirical Capture Model for Fast Neutral Reactions at Low Temperature. J. Phys. Chem. A 2009, 113 (49), 13694-13699. https://doi.org/10.1021/jp905609x.

(77) Talbi, D.; Wakelam, V. KIDA: The New Kinetic Database for Astrochemistry. In Journal of Physics: Conference Series; 2011; p 012029. https://doi.org/10.1088/1742-6596/300/1/012029.

(78) Wakelam, V.; Herbst, E.; Loison, J. C.; Smith, I. W. M.; Chandrasekaran, V.; Pavone, B.; Adams, N. G.; Bacchus-Montabonel, M. C.; Bergeat, A.; Béroff, K.; et al. A Kinetic Database for Astrochemistry (KIDA). Astrophys. Journal, Suppl. Ser. 2012, 199 (1), 21. https://doi.org/10.1088/0067-0049/199/1/21.

(79) Abeysekera, C.; Joalland, B.; Ariyasingha, N.; Zack, L. N.; Sims, I. R.; Field, R. W.; Suits, A. G. Product Branching in the Low Temperature Reaction of CN with Propyne by Chirped-Pulse Microwave Spectroscopy in a Uniform Supersonic Flow. J. Phys. Chem. Lett. 2015, 6 (9), 1599-1604. https://doi.org/10.1021/acs.jpclett.5b00519. 


\section{TOC Graphic}

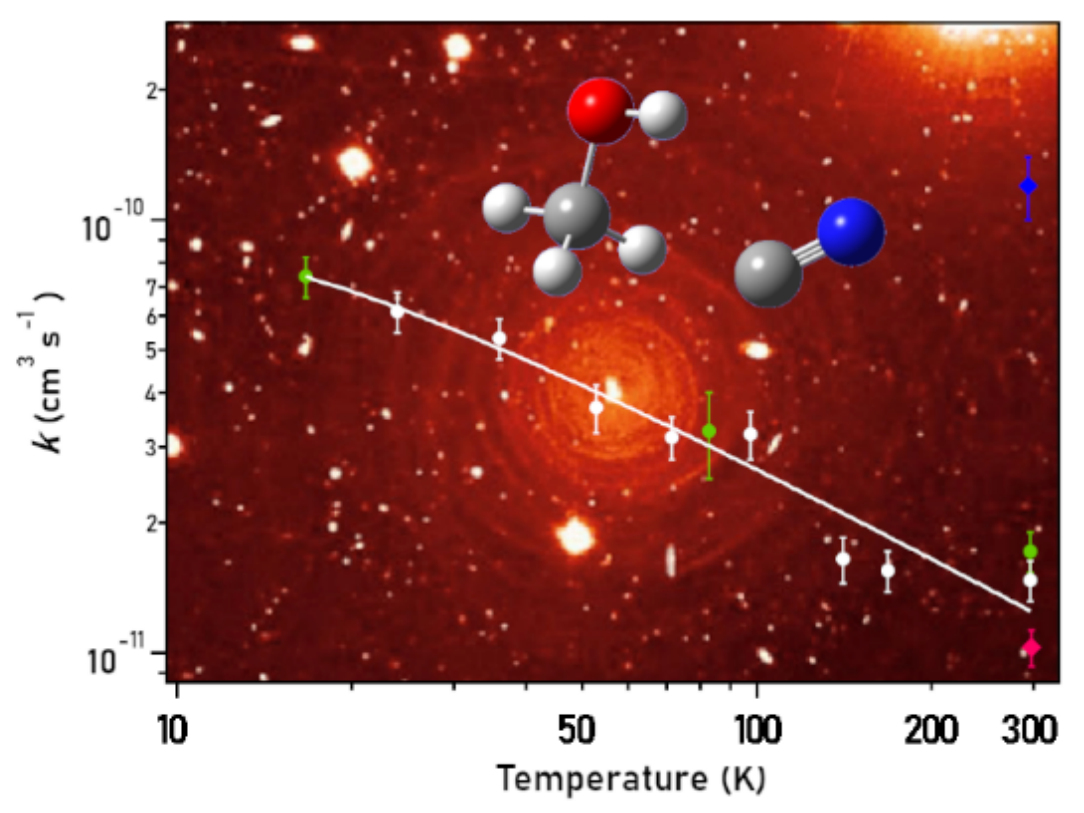

